\title{
Divulgação da responsabilidade social empresarial: como os websites empresariais vêm sendo utilizados por empresas de energia e varejo
}

\section{A Comparison of Corporate Social Responsibility Communication on the Web between the Electricity and Supermarket Sectors}

José Milton de Sousa Filho ${ }^{1}$

Lilian Soares Outttes Wanderley²

\begin{abstract}
Resumo
O fenômeno da Responsabilidade Social das Empresas (RSE) na gestão dos negócios vem sendo cada vez mais debatido, com isso, fazem-se necessários estudos mais diversificados relacionados a esta temática em ascensão. Este trabalho busca analisar em seis grandes empresas dos setores de distribuição de energia e varejo atuantes no Nordeste, como a RSE está sendo divulgada através dos seus websites institucionais, levando em consideração que a internet é uma poderosa ferramenta de comunicação. No referencial teórico são apresentados a evolução dos estudos da RSE e o conceito de marketing social. Os indicadores que auxiliaram na avaliação da divulgação das informações relacionadas à responsabilidade social pela Internet são apresentados na metodologia. O levantamento realizado e a análise de dados não identificaram diferenças muito significativas entre as empresas dos dois setores investigados.
\end{abstract}

Palavras-chave - Responsabilidade Social das Empresas. Balanço Social

\begin{abstract}
Interest on Corporate Social Responsibility (CSR) in Brazil has grown and a large number of academic papers and business discussions have followed, showing the need for more diversity of studies. The Internet has become an important tool for corporations publishing their reports and other types of CSR communication. This paper analyzes how the CSR communication through corporate websites has been published, particularly by comparing two industry sectors: electricity and supermarket. The results show that no major differences were found between these two in the way they publish CSR related information on the web.
\end{abstract}

Keywords - Corporate Social Responsibility. CSR Communication

\section{Introdução}

O fenômeno da Responsabilidade Social das Empresas (RSE) na gestão dos negócios vem sendo muito debatido em congressos e encontros e incentivado por movimentos e institutos empresariais. Assim, fazem-se necessários estudos mais diversificados e aprofundados, relacionados a essa temática em ascensão.

A comunicação das ações, projetos e atividades que envolvem a RSE tem sido colocada em prática pelas empresas através do marketing social, no intuito de gerar vantagens competitivas e, conseqüientemente, melhores imagem e posição na mente dos consumidores. Este artigo busca analisar como a RSE está sendo

\footnotetext{
${ }^{1}$ Mestrando em Administração, Programa de Pós-Gradação em Administração da Universidade Federal de Pernambuco - PROPAD/UFPE. Bacharel em Administração Universidde Federal do Ceará. Universidade Federal de Pernambuco. Câmara de Estudos em Estratégias das Organizações - CEO/PROPAD/DCA/UFPE. Av. Prof. Moraes Rego, 1235 - Cidade Universitária - CEP 50670-901 - Recife/PE - Brasil E-mail : admmiltonfilho@yahoo.com.br

${ }^{2} \mathrm{PhD}$ em Management Studies, University of Cambridge, 2005. Mestre em Administração pelo Programa de Pós-Graduação em Administração da Universidade Federal do Rio Grande do Sul - PPGA/UFRGS, Bacharel em Administração - CEO/PROPAD/DCA/UFPE. Av. Prof. Moraes Rego, 1235 - Cidade Universitária. Recife/PE, Brasil. CEP 50670-901. E-mail : l.outtes@uol.com.br

Artigo recebido em outubro de 2006 e aceito para publicação em dezembro de 2006
} 
divulgada pelas empresas através dos seus websites institucionais, levando em consideração que a Internet é uma poderosa ferramenta de comunicação e vem sendo cada vez mais utilizada pelas organizações (HOLTZ, 2005). Com a Internet, a comunicação entre empresas e consumidores pôde ser facilitada e concretizada de forma mais rápida, sendo uma excelente ferramenta para a comunicação de informações relacionadas à RSE.

Dessa forma, para analisar como as empresas estão utilizando a Internet na divulgação das informações sobre RSE, foram contemplados dois setores importantes, o de distribuição de energia e o de varejo. Esses setores foram escolhidos devido a sua importância para o cenário empresarial e para sociedade, além de terem características muito diferentes, o que possibilita uma melhor análise e interpretação dos dados coletados e demonstra mais claramente as diferenças e similaridades dos setores à luz dos resultados.

\section{Justificativa e objetivos}

A RSE tem-se tornado um dos temas mais debatidos e propagados na gestão empresarial, tornando-se uma variável importante na estratégia competitiva das empresas e na avaliação de seu desempenho. As empresas estão competindo num ambiente de negócios cada vez mais complexo, onde não é suficiente oferecer qualidade e preço competitivo, obedecer às leis e pagar os impostos. As companhias de sucesso serão cada vez mais pressionadas a olharem intensamente os impactos das suas operações, dentro e fora das paredes institucionais, e cuidadosamente verificarem os impactos de suas políticas e ações nos seus empregados, clientes, comunidades e na sociedade como um todo (BORGER, 2001).

Dessa forma, atuando em ambientes competitivos, as empresas necessitam de ferramentas para ajudá-las a comunicar suas ações, projetos e atividades relacionadas à RSE. Segundo Holtz (2005), muitos indivíduos são consumidores de informações. Porém, antes da Internet, o acesso a essas informações era limitado a um pequeno número de pessoas. A Internet mudou esse panorama e hoje é um excelente canal de comunicação, muito utilizado para vender produtos, divulgar informações e conectar pessoas, entre outras funcionalidades.

Assim, torna-se importante o uso da Internet para comunicar as informações relacionadas à RSE, já que a consciência dos consumidores e o ambiente competitivo exercem certa pressão em prol do social. Para verificar como algumas empresas estão trabalhando essa comunicação, foram escolhidos dois setores importantes, o de distribuição de energia e o de varejo.

O interesse em eleger o setor de distribuição de energia como uma das áreas de estudo advém da relevância e da importância que este desempenha na sociedade e no mercado, com seus investimentos e impactos socioeconômicos. Com a privatização das estatais do setor, emergiram grandes empresas controladas pelos capitais nacional e internacional e foram realizados grandes investimentos. Porém, o setor ainda funciona como uma espécie de monopólio, fazendo com que a concorrência e a competitividade entre as empresas sejam baixas ou até mesmo nulas. A característica de ex-estatal também é interessante devido à premissa de que as estatais deveriam obrigatoriamente colaborar com o social, enquanto as empresas privadas poderiam fazer sua escolha entre colaborar ou não. As empresas estudadas foram Celpe, Coelce e Coelba, distribuidoras de energia dos estados de Pernambuco, Ceará e Bahia, respectivamente.

Já o setor de varejo foi escolhido devido à predominância de empresas privadas, alta concorrência e alta competitividade, culminando em decisões estratégicas agressivas, inclusive de marketing, por parte das empresas. Atuam no setor desde microempresas até grandes corporações, e este artigo focou essas últimas devido ao maior potencial de investimento no social. As empresas estudadas foram Bompreço (Wal Mart), Carrefour e Pão de Açúcar, empresas de capitais nacional e internacional que também atuam no Nordeste, como as empresas do setor de energia.

A pesquisa tem como objetivo principal analisar como a RSE está sendo divulgada nos websites das principais empresas do setor de distribuição de energia e do setor de varejo que atuam no Nordeste. Entre os objetivos específicos, podem ser apontados:

- identificar os itens de divulgação da RSE nos websites conforme os indicadores propostos; 
- identificar o direcionamento do investimento social privado efetuado pelas empresas e o seu públicoalvo.

Vale ressaltar que as diferenças significantes entre os setores foram os principais fatores motivadores para que fossem escolhidos, pois dessa forma poderemos verificar, ao final do artigo, se também existem diferenças significantes nas formas de divulgar a RSE em seus websites.

\section{Referencial teórico}

\section{A evolução da responsabilidade social corporativa}

As demandas sociais visando à melhoria das condições de vida da população são geradas de forma constante pela sociedade. Essas demandas visam promover melhorias em educação, infra-estrutura, saúde e lazer, entre outros aspectos, que deveriam ser proporcionadas à população através das ações do poder público. Na visão de Melo Neto e Froes (2001), o Estado deve ser o principal responsável por implementar as melhorias; contudo, em face das limitações da ação estatal, abre-se espaço para que outros agentes atuem nessa frente.

Nesse sentido, Drucker (2002) argumenta que as empresas devem atuar de maneira socialmente responsável, pois estas têm direitos, deveres e obrigações, não se admitindo mais a produção e comercialização de bens e serviços sem a observância aos princípios morais, à postura ética e ao respeito aos conceitos de cidadania. Apoiado nessa visão surge o conceito de RSE, pelo qual as organizações passam a influenciar e a participar das dimensões sociais, buscando com isso vantagens competitivas através de ações, atividades e projetos sociais.

O economista Milton Friedman (1970) expôs seu pensamento em relação ao papel social das empresas. Para o autor, a responsabilidade social pode ser exercida pelas pessoas físicas quando utilizam seu dinheiro em prol do social, e essas pessoas podem ser os executivos ou os donos de uma empresa, por exemplo. Porém, se o executivo passa a gastar não o seu próprio dinheiro e, sim, o capital da firma em ações sociais, não está sendo responsável com seus empregadores nem cumprindo seu papel, que é fazer com que a empresa dê lucro. O autor define as empresas como instituições econômicas que deveriam se restringir à sua tarefa econômica, existindo o perigo das responsabilidades sociais minarem o desempenho econômico da empresa e com ele toda a sociedade. Friedman (1970) argumenta que tornar os administradores responsáveis pela geração de lucro para a firma e pela geração de bem-estar para a sociedade reflete uma contradição que pode vir a causar a morte da empresa. Para o autor, há somente uma responsabilidade social para os negócios, a utilização dos recursos para gerar o maior lucro possível, dentro das regras legais e sem a utilização de fraudes. Dessa forma, com o crescimento dos negócios, seria possível uma maior geração de empregos e uma maior transferência de recursos para o Estado através dos impostos, que seriam revertidos em melhorias em prol da sociedade.

Porém, a visão de Friedman vem sendo rebatida por alguns teóricos, a exemplo de Drucker (2002), que examina a RSE como uma área onde a empresa decide qual será seu papel na sociedade, estabelece seus objetivos sociais, suas metas de desempenho e de influências na sociedade onde atua.

Drucker (2002) argumenta ainda que na sociedade pós-capitalista não se pode afirmar que uma empresa tenha somente o desempenho econômico como único propósito. Porém, o desempenho econômico é a sua primeira responsabilidade, pois a empresa que não trabalha para obter lucro pelo menos igual ao custo de seu capital é irresponsável, pois está desperdiçando recursos da sociedade. Contudo, toda empresa deve assumir plena responsabilidade pelo impacto causado sobre os funcionários, o meio ambiente, os clientes e tudo com o qual se relaciona.

Desde a década de 1960, alguns teóricos já se preocupavam com a temática da RSE, mostrando que a relevância da atuação social das empresas não podia ser deixada de lado pelos gestores e afirmando que as empresas são agentes que têm um papel importante na sociedade, que vai além da geração de lucros para os acionistas, conforme advogava o economista Milton Friedman (1970).

Segundo Karkotli (2004), já em meados da década de 1960, Drucker se mostrava preocupado com a conscientização das empresas no tocante às suas verdadeiras responsabilidades para com a sociedade. 
Declarava a preocupação com a estrutura organizacional e com as interações da empresa com seus públicos internos e externos. Drucker lembra que a administração é igualmente responsável por garantir que as ações e decisões presentes da empresa não criem futuras reivindicações, medidas políticas e opiniões públicas que possam ameaçá-la.

Também na década de 1960, o autor Joseph W. McGuire (1963 apud CARROLL, 1999, p.4), em seu livro Business and society, já se preocupava com as questões sociais empresariais, expondo que "a idéia de responsabilidades sociais supõe que a corporação não tem somente obrigações econômicas e legais, mas também responsabilidades com a sociedade que se estendem para além dessas obrigações". Segundo Carroll (1999), McGuire argumentou que as corporações devem ter interesses em política, no bem-estar da comunidade, na educação, nos seus funcionários e na vida social em geral. Conseqüentemente, a empresa deve agir de maneira justa e ética nos negócios.

Já na década de 1970, Davis (1973, apud BORGER, 2001) argumenta que é obrigação das empresas avaliarem os efeitos de suas decisões nas esferas sociais, de maneira a integrar benefícios sociais e não somente buscar vantagens econômicas. $\mathrm{O}$ autor argumenta que a RSE começa onde termina a lei, já que existe a obrigatoriedade do cumprimento desta. Assim, pagar impostos e salários justos não são caracterizados como RSE, e sim obrigações que a empresa deve cumprir.

No final da década de 1970, Carroll (1979) apresenta seu modelo integrado em três dimensões da RSE. Segundo o autor, esta pode ser dividida em quatro categorias, a primeira, denominada econômica, pressupõe que a empresa deve atuar para ser lucrativa; a categoria legal declara que a empresa deve obedecer e respeitar as leis; a categoria ética informa que a empresa deve preocupar-se com danos à ética e a moral ao executar suas ações; e na categoria filantrópica ou discricionária, a empresa deve tomar decisões levando em consideração a sociedade e o meio social em que vive e de forma voluntária. Vale ressaltar que essas categorias se completam e não são exclusivas entre si; ou seja, todas devem ser colocadas em prática ao mesmo tempo sem que uma acarrete prejuízo às demais.

Na década de 1990, Carroll (1999) traça uma linha histórica sobre a evolução do conceito de RSE. O estudo mostra que na literatura de negócios, os conceitos são os mesmos. Porém, a evolução se dá diante da forma como as questões sociais são tratadas e nas diferentes práticas de RSE, devido à evolução da sociedade como um todo.

Segundo Pasa (2004), Carroll foi um dos autores que melhor definiu responsabilidade social empresarial; isto é, trouxe o conceito mais conhecido e aceito. A descrição da responsabilidade social de uma empresa incluindo as categorias econômicas, legais, éticas e voluntárias, conforme explicado anteriormente.

Em uma abordagem atual, o Instituto Ethos de Empresas e Responsabilidade Social conceitua o tema da seguinte forma:

Responsabilidade social é uma forma de conduzir os negócios da empresa de tal maneira que a torna parceira e co-responsável pelo desenvolvimento social. A empresa socialmente responsável é aquela que possui a capacidade de ouvir os interesses das diferentes partes (acionistas, funcionários, prestadores de serviço, fornecedores, consumidores, comunidade, governo e meio ambiente) $e$ consegue incorporá-los no planejamento de suas atividades, buscando atender às demandas de todos e não apenas dos acionistas ou proprietários. (ETHOS, 2000)

A evolução das empresas acompanha a evolução da sociedade; com isso surgem mercados mais competitivos onde as empresa precisam garantir sua permanência. Nesse sentido, Ashley (2002) argumenta que a busca de alternativas para garantir crescimento e sobrevivência no mercado de alta competitividade tem estado permanentemente na agenda dos gestores organizacionais. É crescente a utilização de estratégias e processos que melhor traduzam, junto com o lucro, a sensibilidade e sintonia das organizações com as necessidades de seus clientes, internos e externos, relativas a questões de qualidade de produtos ou serviços oferecidos, à proteção e uso adequado de recursos do meio ambiente e a relações éticas e justas com trabalhadores, fornecedores e governos; ou seja, questões que retratam a atuação socialmente responsável das organizações. 
Conforme a evolução do conceito relatado anteriormente, pode-se concluir que a RSE há muito é uma preocupação dos teóricos, pois as empresas são responsáveis pelos impactos que suas atividades causam na sociedade e devem se responsabilizar por isso. Além disso, uma questão mais atual é que a RSE é hoje fonte de vantagens e diferenciais competitivos, que devem ser perseguidos pelas empresas que buscam maior competitividade e melhores resultados.

\section{Uma breve explanação sobre marketing social}

Segundo Dufloth e Bellumat (2005), a disseminação de informações sobre as ações de responsabilidade social das empresas fortalece os resultados sociais pretendidos. Essa prática pode integrar os diversos públicos internos e externos envolvidos e facilitar a relação com os funcionários, clientes, fornecedores, comunidade e com a sociedade em geral. Assim, nesse contexto, surge o conceito de marketing social empresarial.

Contudo, faz-se necessário apresentar o conceito de marketing tradicional, no intuito de mostrar como definições importantes geram novos conceitos e como estes podem ser utilizados de diferentes perspectivas. Segundo Kotler (2000, p.30), "marketing é um processo social por meio do qual pessoas e grupos de pessoas obtêm aquilo de que necessitam e o que desejam com a criação, oferta e livre negociação de produtos e serviços de valor com outros". Kotler (1998, p.27) complementa seu conceito destacando que "marketing significa trabalhar com mercados para realizar trocas potenciais com o propósito de satisfazer necessidades e desejos humanos".

Segundo Cobra (1997, p. 23) marketing é "[...] o processo na sociedade pelo qual a estrutura da demanda para bens econômicos e serviços é antecipada ou abrangida e satisfeita através da concepção, promoção, troca e distribuição física de bens e serviços".

No entanto, Kotler (2000) chama atenção para o fato de que as empresas devem avaliar constantemente se estão praticando marketing de forma ética e socialmente responsável. Sugere uma reflexão sobre técnicas de vendas que invadem a privacidade das pessoas, sobre técnicas de pressão para forçar as pessoas a comprar e sobre a aceleração da obsolescência de bens.

De acordo com essa visão, Kotler (2000, p.47) propõe uma ampliação da concepção tradicional de marketing, buscando uma orientação mais preocupada com a sociedade, e o definiu como marketing societal ou marketing social:

A orientação de marketing societal sustenta que a tarefa da organização é determinar as necessidades, os desejos e os interesses dos mercados-alvo e fornecer satisfações desejadas mais eficaz $e$ eficientemente do que a concorrência, de uma maneira que preserve ou melhore o bem-estar do consumidor e da sociedade.

O autor complementa afirmando que a orientação de marketing societal exige que as empresas incluam considerações sociais e éticas em suas práticas de marketing e que devem manter equilibradas três considerações freqüentemente conflitantes. São elas: lucros para a empresa, satisfação dos desejos dos consumidores e interesse público.

A expressão marketing social surgiu nos Estados Unidos, em 1971, e foi usada pela primeira vez por Kotler e Zaltman que, na época, estudavam aplicações do marketing que contribuíssem para a busca e o encaminhamento de soluções para as diversas questões sociais. Kotler e Zaltman (1971) conceituaram marketing social como o processo de "criação, implementação e controle de programas implementados para influenciar a aceitabilidade das idéias sociais e envolvendo considerações relativas ao planejamento de produto, preço, comunicação, distribuição e pesquisa de marketing".

Outra definição para marketing social é encontrada no trabalho de Kotler e Roberto (1992, p.25), onde os autores ampliam o escopo do conceito e o tratam como uma tecnologia para a mudança social: 


\section{[...] uma tecnologia de administração da mudança social, associada ao projeto, à implantação e ao} controle de programas voltados para o aumento da disposição de aceitação de uma idéia ou prática social em um ou mais grupos de adotantes escolhidos como alvo.

Segundo Schiavo (2006), uma interpretação mais recente identifica o marketing social como uma metodologia inovadora, capaz de gerar a evolução do modo de lidar com idéias, atitudes, conceitos, ações, comportamentos e práticas, visando promover transformações sociais específicas. Ainda conforme o autor, um programa de marketing social deve atingir uma grande audiência em um curto período, assegurando tanto as mudanças comportamentais planejadas quanto a sua continuidade no longo prazo, assim, colocando em prática o conceito de efetividade.

Conforme os conceitos vistos anteriormente, pode-se concluir que o marketing social empresarial consiste em um conjunto de atividades, técnicas, ferramentas e estratégias que tratam do esforço mercadológico de relacionar causas e projetos sociais a uma marca ou organização. Além disso, essas estratégias buscam estimular e promover mudanças sociais, fazendo com que a empresa exercite uma postura condizente com as demandas da sociedade por ações socialmente responsáveis. Assim, no marketing social são empregados conceitos e ferramentas originárias do marketing tradicional para influenciar comportamentos com o objetivo de promover as mudanças sociais.

\section{Metodologia da pesquisa}

A pesquisa realizada pode ser classificada em dois aspectos, quanto aos fins e quanto aos meios (VERGARA, 2005). Quanto aos fins, a pesquisa foi exploratória e descritiva. Exploratória porque, embora atualmente muito se tenha publicado sobre RSE, pouco foi explorado sobre sua divulgação através dos websites das empresas como uma estratégia para comunicar as ações e os projetos destas para a sociedade. Descritiva porque visa descrever como essa divulgação vem sendo feita por algumas empresas dos setores de distribuição de energia e varejo que atuam no Nordeste, buscando constatar suas diferenças e similaridades.

Quanto aos meios, a pesquisa foi bibliográfica e empírica, pois para fundamentação teórica do estudo foi realizada investigação sobre a evolução da responsabilidade social empresarial e do marketing social, bem como seus principais teóricos e os conceitos atualmente aceitos. Além disso, as informações desejadas foram coletadas pela Internet, através da avaliação dos websites das empresas escolhidas, caracterizando uma pesquisa teórico-empírica.

Foi proposto pelos autores um conjunto de indicadores que visam auxiliar na avaliação dos itens de divulgação da RSE nos websites da empresas pesquisadas. Vale ressaltar que este estudo não visa julgar a legitimidade, intensidade e o sucesso das atividades relacionadas à SER; visa apenas constatar como a divulgação dessas atividades está sendo feita pelos websites institucionais dessas empresas.

\section{Indicadores de divulgação da responsabilidade social empresarial}

Os indicadores dizem respeito à divulgação das atividades relacionadas à RSE nos websites institucionais das empresas. Esses indicadores foram elaborados a partir da experiência dos autores na área, pois, até então, não foram achados referenciais teóricos que tratassem da utilização da Internet como ferramenta para divulgação da responsabilidade social pelas empresas. Assim, os seguintes indicadores podem ser considerados pioneiros e importantes para essa análise:

- divulgação do código de conduta ou código de ética da empresa;

- divulgação de informações especificando quais são os projetos sociais internos e/ou externos;

- divulgação dos resultados dos projetos sociais diretamente no website, especificando quantidade de pessoas e organizações atendidas, benefícios para o público-alvo, recursos humanos, financeiros e materiais investidos, entre outras informações; 
- identificação dos possíveis parceiros relacionados à RSE, como organizações locais, regionais, nacionais ou internacionais;

- divulgação do balanço social nos modelos Ibase, Global Reporting Initiative (GRI) ou próprio.

\section{Coleta de dados}

A coleta de dados foi feita através da Internet, onde foram observados, explorados e analisados os websites das empresas escolhidas. As visitas foram feitas e as informações coletadas durante os meses de março e abril de 2006. Os websites visitados foram os seguintes:

- Celpe - www.celpe.com.br

- Coelce - www.coelce.com.br

- Coelba - www.coelba.com.br

- Pão de Açúcar - www.grupopaodeacucar.com.br/www.institutopaodeacucar.com.br

- Carrefour - www.carrefour.com.br

- Bompreço - www.bompreco.com.br

- Wal Mart - www.walmartbrasil.com

\section{Resultados}

Os resultados das análises serão relatados e discutidos, valendo ressaltar que buscam responder aos objetivos específicos propostos no início do estudo. São eles: (a) identificar os itens de divulgação da RSE nos websites conforme os indicadores propostos; e (b) identificar o direcionamento do investimento social privado efetuado pelas empresas e o seu público-alvo. As críticas à legitimidade e ao sucesso das atividades relacionadas à RSE não serão feitas, pois não fazem parte do escopo do estudo nem dos objetivos propostos. Iniciaremos os resultados pelas empresas do setor de distribuição de energia.

\section{Celpe}

No website da Celpe, empresa que atua no estado de Pernambuco, encontra-se facilmente o link que leva à página com informações relacionadas à RSE. Logo no início dessa página, vê-se o texto a seguir, que mostra o compromisso socioambiental de empresa:

A vida em sociedade exige a participação de todos. Cidadãos e entidades, públicas ou privadas, precisam trabalhar em prol do desenvolvimento social, da melhoria de vida da comunidade e da preservação do meio ambiente. Ciente desse papel e dos desafios de participar das transformações do contexto onde atua, a Celpe tem entre seus compromissos contribuir para a melhoria social, econômico e ambiental do estado de Pernambuco.

A empresa possui um programa de RSE que, segundo o website, tem como objetivo organizar as práticas sociais já existentes na empresa, além de propor novas ações para a melhoria da qualidade de vida dos seus empregados, clientes, fornecedores, acionistas e a comunidade. Nas ações destinadas à comunidade, o foco são crianças, adolescentes e jovens em situação de vulnerabilidade social, caracterizando assim seu público-alvo. A empresa atua nas áreas de educação, meio ambiente, arte e cultura, através do projeto Energia Solidária, caracterizando assim o direcionamento de seus investimentos.

Conforme o website, o projeto Energia Solidária compreende as ações realizadas pela empresa para incentivar e apoiar o envolvimento dos empregados e familiares em atividades de voluntariado na comunidade (Escola dos Voluntários Celpe), buscando contribuir com a transformação da realidade e construção de um futuro melhor para crianças, adolescentes e jovens do estado de Pernambuco. 
Após a análise, pode-se constatar que constam informações sobre os projetos, e algumas parcerias, bem como o balanço social dos anos de 2004 e 2005, que estão disponíveis para download. Porém, não constam informações sobre o código de ética e os resultados dos projetos, dados considerados importantes para este estudo. Assim, a Celpe atende a apenas três indicadores dos cinco propostos.

\section{Coelba}

Ao entrar no website da Coelba, empresa que atua no estado da Bahia, pode-se constatar a presença do código de ética, onde constam os princípios, valores, normas de conduta profissional e conduta no relacionamento com os diversos stakeholders (clientes, fornecedores, prestadores de serviço, concorrentes, sociedade e acionistas).

A empresa tem um programa de RSE chamado Energia para Crescer, que tem como objetivo principal nortear todas as ações da empresa, para que estejam vinculadas aos princípios de RSE e alinhadas com as diretrizes e com os focos de atuação adotados. Segundo o website, essa política está presente em todas as relações da empresa com seus diversos públicos e o acompanhamento de todo o processo é feito pelo Comitê de Responsabilidade Social e por sete grupos, compostos por colaboradores de diversos departamentos, que tratam dos seguintes temas: valores e transparência, público interno, meio ambiente, fornecedores, consumidores e clientes, governo e sociedade e comunidade. O principal foco e os investimentos do programa Energia para Crescer estão nas ações voltadas para educação, cultura e meio ambiente.

Segundo o website, são investidos $\mathrm{R} \$ 8,3$ milhões por ano em seis projetos relacionados à educação, que beneficiam 1,4 milhão de alunos em mais de 500 escolas. No entanto os projetos não são divulgados no website. Já em relação às ações voltadas para cultura, a empresa patrocina projetos e produções culturais, tendo atingido uma marca de mais de 120 projetos. Porém, novamente, não há divulgação de quais são esses projetos.

Constam várias informações relacionadas às ações de meio ambiente, inclusive a política ambiental, acordos e convênios firmados com prefeituras, órgãos governamentais, não-governamentais e universidades, visando ao investimento e à cooperação em projetos. Além disso, estão disponíveis para download, manuais de coleta seletiva, arborização e boletins ambientais trimestrais que divulgam as ações da empresa nessa área. Estão disponíveis também os balanços sociais dos anos de 2001, 2002, 2003 e 2004.

Dessa forma, pode-se concluir que de acordo com os indicadores propostos, a empresa divulga seu código de conduta e suas parcerias, além de publicar o balanço social. Porém, deixa a desejar em relação às informações sobre os projetos e resultados nas áreas de educação e cultura. Assim, a Coelba atende a apenas a três indicadores.

\section{Coelce}

No website da Coelce, empresa que atua no estado do Ceará, pode-se encontrar rapidamente o link "responsabilidade social e ambiental", no qual consta o compromisso da empresa, conforme transcrito a seguir:

A COELCE é consciente de que a proteção à natureza e ao meio ambiente deve ser considerada em qualquer atividade econômica, já que disto dependerão as gerações futuras. É por essa razão que decidiu desenvolver todas as suas atividades empresariais respeitando o meio ambiente $e$ comprometendo-se com a eficiência energética, devido à escassez dos recursos naturais não renováveis. Para superar o desafio meio ambiental, a COELCE vai além do estrito cumprimento das legislações vigentes, intensificando as ações necessárias e estabelecendo os procedimentos adequados para garantir o uso racional dos recursos e a minimização do impacto ambiental, contribuindo, assim, para o desenvolvimento sustentável demandado pela sociedade.

A política de RSE é mostrada e explicada na mesma página e engloba os seguintes tópicos: (a) transparência, compromisso ético da empresa com os seus stakeholders; (b) diversidade, respeito aos elementos da diversidade, como cultura; (c) desenvolvimento auto-sustentável, inclusão social sem visar à filantropia; (d) associação, parcerias com a iniciativa privada, governo e terceiro setor para realização das ações sociais; (e) complementariedade, parceira para o desenvolvimento sustentável; (f) inclusão, ações sociais 
funcionam em busca da inclusão social; e (g) participação, ações sociais implementadas pelos funcionários, buscando fortalecer o relacionamento interno.

Segundo informações do website, o foco das ações sociais são crianças e adolescentes em áreas de risco, caracterizando o público-alvo das ações da empresa. Porém, não se encontram relacionados os projetos e ações que a organização está implementando ou implementou, nem as áreas de atuação e nem as parcerias para as ações, que inclusive fazem parte da política da empresa. Pode-se constatar que estão disponíveis para download os balanços sociais dos anos de 2003 e 2004.

Pode-se concluir, conforme os indicadores, que a Coelce divulga seu balanço social no website, porém deixa a desejar, pois não divulga seu código de ética, projetos, resultados dos projetos e parcerias. Assim, a empresa atende a somente um indicador.

\section{Pão de Açúcar}

Ao entrar no website do Pão de Açúcar, rapidamente encontra-se o link que leva ao Instituto Pão de Açúcar, executor da política de RSE da empresa. Na página do instituto, logo se encontra o seguinte texto: "o objetivo do Instituto Pão e Açúcar é contribuir para a melhoria da qualidade de vida de crianças, jovens, famílias e comunidade". Consta que, para atingir esse objetivo, a organização desenvolve programas educacionais nas áreas de ampliação de linguagens, música, esporte e preparação para o trabalho, através das "casas" atuantes nas cidades do Rio de Janeiro, São Paulo, Brasília e Fortaleza, ou por meio de parcerias com organizações públicas e instituições da comunidade. Dessa forma, pode-se afirmar que o direcionamento do investimento é para as ações de educação. Cada área anteriormente descrita conta com projetos diversificados para crianças e jovens de diferentes faixas etárias que vão dos 7 aos 21 anos, caracterizando assim seu público-alvo.

Pode-se constatar que não estão disponíveis informações sobre código de conduta, resultados dos projetos, parcerias e balanço social, nem no website da empresa, nem do instituto. Constam somente informações detalhadas sobre os projetos. Assim, o Pão de Açúcar atende a somente um dos indicadores.

\section{Carrefour}

Na página de RSE da empresa, denominada "Carrefour e a Comunidade", encontra-se inicialmente o texto a seguir, que demonstra a política e o principal foco das ações:

A política de sustentabilidade do Grupo Carrefour alia, com o comprometimento de todos os níveis da empresa, as exigências econômicas com as necessidades sociais e o respeito aos recursos naturais. $\mathrm{Na}$ gestão dos negócios, incluímos a responsabilidade social com princípios e ações que favorecem o desenvolvimento sustentável e agregam valor ao relacionamento com os vários públicos. Atenção especial recebem as comunidades onde estão instaladas as nossas lojas. Estimulamos, contribuímos e participamos de seu crescimento social. A educação é o foco predominante dessa atuação.

A empresa possui projetos nas áreas de educação e meio ambiente, apesar do foco estar na primeira área. Constam informações sobre as ações de incentivo ao voluntariado, como prêmios, por exemplo, e a explicação dos vários projetos que fazem parte do portfólio da empresa. Alguns deles são "Aula de Cidadania", "Voluntário Carrefour" e "Projeto Verde". Cada projeto tem um público-alvo específico, de crianças a adultos, passando por jovens e adolescentes, todos de classe baixa. Os projetos nos quais existem parcerias são relacionados e explicados, bem como os parceiros são identificados. O balanço social, nesse caso, denominado relatório social, está disponível no formato do modelo internacional Global Report Initiative (GRI), mas consta somente a versão do ano de 2003.

Dessa forma, pode-se concluir que a empresa divulga seus projetos e suas parcerias, bem como seu balanço social. Porém, as informações sobre o código de ética e os resultados dos projetos não estão disponíveis no website. Assim, o Carrefour atende a somente três indicadores. 


\section{Bompreço/Wal Mart}

Inicialmente, foi visitado o website da rede de supermercados Bompreço, a qual foi recentemente adquirida pela multinacional americana Wal Mart. Porém, não foram encontradas informações sobre as ações de RSE da empresa. Assim, o próximo passo foi buscar informações no website brasileiro da empresa americana.

Conforme se pode constatar na citação adiante, o Wal Mart divulga uma orientação voltada para ações relacionadas ao meio social, focando as comunidades no entorno das áreas onde as lojas estão localizadas.

O investimento nas comunidades em que atuamos é uma parte fundamental da nossa cultura. Sam Walton acreditava em liderança servidora - ou seja, acreditava que os líderes da empresa deveriam servir aos associados e clientes com integridade. A função de servir da empresa desdobra-se então à comunidade ao seu redor. O Wal-Mart está profundamente envolvido com as comunidades em que atua.

De acordo com o website, as ações podem variar de acordo com a comunidade do entorno e suas necessidades. Assim, existem projetos relacionados à saúde, educação e meio ambiente, entre outros. Contudo, as ações da empresa voltadas à comunidade estão focadas principalmente em duas questões: a causa da criança e do adolescente e o combate à fome. Segundo o website, os projetos são desenvolvidos em parceria com organizações sem fins lucrativos e em todas as unidades existem equipes de funcionários responsáveis pelas ações. Esses projetos estão relacionados e explicados e as respectivas organizações parceiras citadas. Entretanto, os resultados não são mencionados.

Ainda segundo o website, A empresa colabora com mais de 100 entidades beneficentes, entre elas escolas, creches, casas de repouso e orfanatos. Porém, essas organizações e o número de beneficiados não são divulgados. Por fim, o balanço social não está disponível, nem existe menção a ele.

Pode-se concluir, à luz dos indicadores propostos, que o Wal Mart divulga seus projetos e suas parcerias. Porém, deixa a desejar, pois não estão disponíveis informações sobre o código de conduta, os resultados dos projetos e o balanço social. Assim, a empresa atende a somente dois indicadores.

\section{Conclusão}

Este estudo buscou mostrar, através de indicadores propostos, como está sendo feita a divulgação das ações relacionadas à RSE nos websites de seis importantes empresas dos setores de distribuição de energia e varejo atuantes em estados da região Nordeste.

A RSE é vista atualmente como fator diferenciador, e em mercados competitivos pode ser utilizada como geradora de vantagens competitivas para quem a põe em prática (ASHLEY, 2002). Assim, a divulgação das ações de responsabilidade social pode ser então caracterizada como uma ação importante na busca por melhores resultados.

De acordo com o quadro 1, onde os resultados da pesquisa estão sintetizados, pode-se constatar que nenhuma das empresas divulga os resultados dos projetos, informação muito importante para que os stakeholders e a sociedade em geral possam avaliar a efetividade das ações empreendidas pelas organizações, caracterizando assim, um erro estratégico por parte destas. 
Quadro 1

Sintese dos resultados

\begin{tabular}{|c|c|c|c|c|c|c|}
\hline & \multicolumn{6}{|c|}{ INDICADORES } \\
\hline \multirow{7}{*}{ 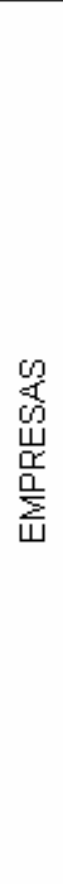 } & & $\begin{array}{l}\text { Código de } \\
\text { Ética ou } \\
\text { Conduta }\end{array}$ & $\begin{array}{c}\text { Projetos } \\
\text { Sociais }\end{array}$ & $\mid \begin{array}{c}\text { Resultados do } \\
\text { Projetos }\end{array}$ & Parcerias & $\begin{array}{c}\text { Balanço } \\
\text { Social }\end{array}$ \\
\hline & Celpe & NÄO & $\mathrm{SIM}$ & NÄO & SIM & SIM \\
\hline & Coelba & $\mathrm{SIM}$ & NÄO & NÄO & $\mathrm{SIM}$ & $\mathrm{SIM}$ \\
\hline & Coelce & $\mathrm{NÄO}$ & NÄO & NÃO & NÄO & SIM \\
\hline & $\begin{array}{l}\text { Pẫo de } \\
\text { Açúcar }\end{array}$ & $\mathrm{NÃO}$ & SIM & NÃO & $\mathrm{NÄO}$ & NÄO \\
\hline & Carrefour & NÃO & SIM & NÄO & SIM & SIM \\
\hline & $\begin{array}{l}\text { Bompreço } \\
\text { Wal Mart }\end{array}$ & NÄO & SIM & NÄO & SIM & NÃ̃O \\
\hline
\end{tabular}

Fonte: adaptado dos websites corporativos, dados coletados no período março-abril de 2006.

Outro indicador pouco atendido, a divulgação do código de ética ou conduta, mostrou que somente a Coelba o divulga publicamente em seu website, mostrando preocupação com uma gestão transparente e comunicando isso à sociedade.

O indicador divulgação de projetos sociais mostrou-se bem utilizado pelas empresas varejistas, pois todas divulgam, mostrando assim a importância desse item. Porém, entre as empresas de energia, somente a Celpe se preocupou em comunicar pela Internet seus projetos sociais. Já no indicador divulgação do balanço social, ocorreu o contrário, as empresas de energia tiveram um melhor desempenho, já que todas publicam em seu website, e das varejistas, somente o Carrefour teve essa preocupação. A presente análise mostra a paridade das formas de comunicação da RSE pela Internet entre as empresas dos diferentes setores.

Em mercados competitivos, como é o caso do varejo de supermercado, onde a concorrência é forte e o ambiente turbulento, concluiu-se que se fazem necessários uma melhor comunicação e divulgação das ações de RSE por parte das empresas estudadas. As empresas varejistas estão divulgando suas ações no mesmo "nível" das empresas do setor de distribuição de energia, porém, estas estão em um setor de baixa concorrência e atuam quase como monopólio.

Assim, não foram encontradas diferenças significativas nas formas de divulgação da RSE pela Internet entre as empresas estudadas nos dois setores. Apesar da RSE ser atualmente considerada um fator importante para a conquista de novos clientes e mercados, os resultados mostram que sua divulgação através da Internet está equiparada.

Isso nos leva a concluir que apesar de ser atualmente considerada estratégica, a RSE não está sendo divulgada pela Internet de maneira adequada e que apesar das significativas diferenças entre os setores, não existem 
diferenças da mesma grandeza na divulgação das informações referentes à RSE por parte das empresas; ou seja, nesse caso, o setor não influenciou as informações divulgadas.

A atuação socialmente responsável deve estar centrada na estratégia das empresas. No entanto, estas devem conhecer as necessidades de criação e implementação de novos projetos de acordo com seu negócio fim e com o ambiente no qual estão inseridas, o mercado e a comunidade. Além disso, os gestores devem estar atentos às necessidades dos stakeholders e da sociedade em geral, pois dessa forma a empresa atingirá melhores resultados econômicos e sociais, o que, conforme os pensamentos de Peter Drucker, é o principal papel das empresas. 


\section{Referências}

ASHLEY, P. A. Ética e responsabilidade social nos negócios. São Paulo: Saraiva, 2002.

BORGER, F. G. Responsabilidade social: efeitos da atuação social na dinâmica empresarial. 254f. Tese (Doutorado em Administração) Programa de Pós-Graduação em Administração, Universidade de São Paulo, São Paulo, 2001.

CARROLL, A. B. A three-dimensional conceptual model of corporate performance. The Academy of Management Review, n.4, p.17-25, 0ct. 1979.

Corporate social responsibility. Business and Society, v.38, n.3, p.268-295, Sept. 1999.

COBRA, M. Marketing básico: uma abordagem brasileira. 4.ed. São Paulo: Atlas, 1997.

ETHOS. Instituto de Empresas e Responsabilidade Social. Indicadores Ethos de responsabilidade social - versão 2000. São Paulo, 2000. Disponivel em: <www.ethos.org.br>.

FRIEDMAN, M. The social responsibility of business is to increase its profits. The New York Times Magazine, 13 Sept. 1970.

DRUCKER, P. Fator humano e desempenho: o melhor de Peter Drucker sobre administração. São Paulo: Pioneira, 2002.

DUFLOTH, S. C.; BELLUMAT, R. C. C. A disseminação de informações das ações de responsabilidade social das empresas. In: XXIX ENCONTRO ANUAL DA ANPAD, Brasília. Anais... Rio de Janeiro, ANPAD, 2005.

HOLTZ, S. The impact of new technologies on internal communication. Strategic Communication Management, v.10, n.1, Dec. 2005.

KARKOTLI, G. R. Responsabilidade social: uma estratégia empreendedora. 205f. Tese (Doutorado em Engenharia de Produção) - Programa de Pós-Graduação em Engenharia de Produção, Universidade Federal de Santa Catarina, Florianópolis, 2004.

KOTLER, P. Administração de marketing: análise, planejamento, implementação e controle. 5.ed. São Paulo: Atlas, 1998.

Administração de marketing: a edição do novo milênio. São Paulo: Prentice Hall, 2000.

; ROBERTO, E. L. Marketing social: estratégias para alterar o comportamento público. Rio de Janeiro: Campus, 1992.

;ZALTMAN, G. Social marketing: an approach to planet social change. Journal of Marketing, Oct./Nov. 1971.

MELO NETO, F. P.; FROES, C. Gestão da responsabilidade social corporativa: o caso brasileiro. Rio de Janeiro: Qualitymark, 2001.

PASA, C. R. R. ECP-Social: um modelo de avaliação da performance social empresarial. 276f. Tese (Doutorado em Engenharia de Produção)

- Programa de Pós-Graduação em Engenharia de Produção, Universidade Federal de Santa Catarina, Florianópolis, 2004.

SCHIAVO, M. R. Conceito e evolução do marketing social. Disponivel em: <www.socialtec.org.br>. Acesso em: 18 abr. 2006.

VERGARA, S. C. Projeto e relatórios de pesquisa em administração. 6.ed. São Paulo: Atlas, 2005 